\title{
FREDERICK SALMON: FOUNDER OF ST. MARK'S HOSPITAL, LONDON
}

\author{
by
}

\section{GUTHBERT E. DUKES}

THE retirement of a senior surgeon from the staff of a hospital in which he has worked for many years is often an impressive occasion. How much more so when the surgeon is actually the founder of the hospital to which he has given the best years of his life! So it was one hundred years ago with Frederick Salmon, the Founder of St. Mark's Hospital, who retired from the active staff in the year I859. To mark the occasion the Hospital Committee presented him with a portrait, painted by Francis Grant, R.A. (Fig. I), and this has hung in the boardroom of the hospital ever since. Facing this on the opposite wall of the hospital boardroom is a similar painting of Alderman William Taylor Copeland, Lord Mayor of London $1835-6$ (painted by James Ward, R.A., in 1854) (Fig. 2). William Taylor Copeland gave generous support to Salmon in the early years and established the tradition, continued ever since, whereby the reigning Lord Mayor of London pays an annual visit to the hospital to preside at the annual general meeting. Alderman W. T. Copeland was the first president of the hospital.

Frederick Salmon is remembered partly for his books on stricture and other diseases of the rectum, partly for his outspoken criticisms of the constitution of the Royal College of Surgeons, but chiefly of course as the Founder of St. Mark's Hospital.

He was born at Bath in 1796 . After serving his medical apprenticeship in the west of England he came to London as a medical student at St. Bartholomew's Hospital. He obtained the L.S.A. in March 1817 and M.R.G.S. in April 1818 and was appointed as house surgeon at Barts. He began to specialize in surgery and was elected surgeon to the General Dispensary in Aldersgate Street in 1827 but resigned in 1832 owing to a dispute with the committee concerning appointments to the staff.

\section{Salmon's Book on Stricture of the Rectum}

Soon after qualification Salmon settled in practice at 12 Old Broad Street, and began to take a special interest in rectal disease, possibly because he had served his apprenticeship in Bath where patients with intestinal diseases tended to congregate for the purpose of 'taking the waters'. In January 1828 he published a book on stricture of the rectum the object of which was 'to prove that stricture of the rectum is a very common disease ... and that surgery furnishes us with means adequate to its removal, or alleviation'. This seems to have met a popular need because the first edition soon sold out and a second was published seven months later (July I828). In the preface to this the author says 


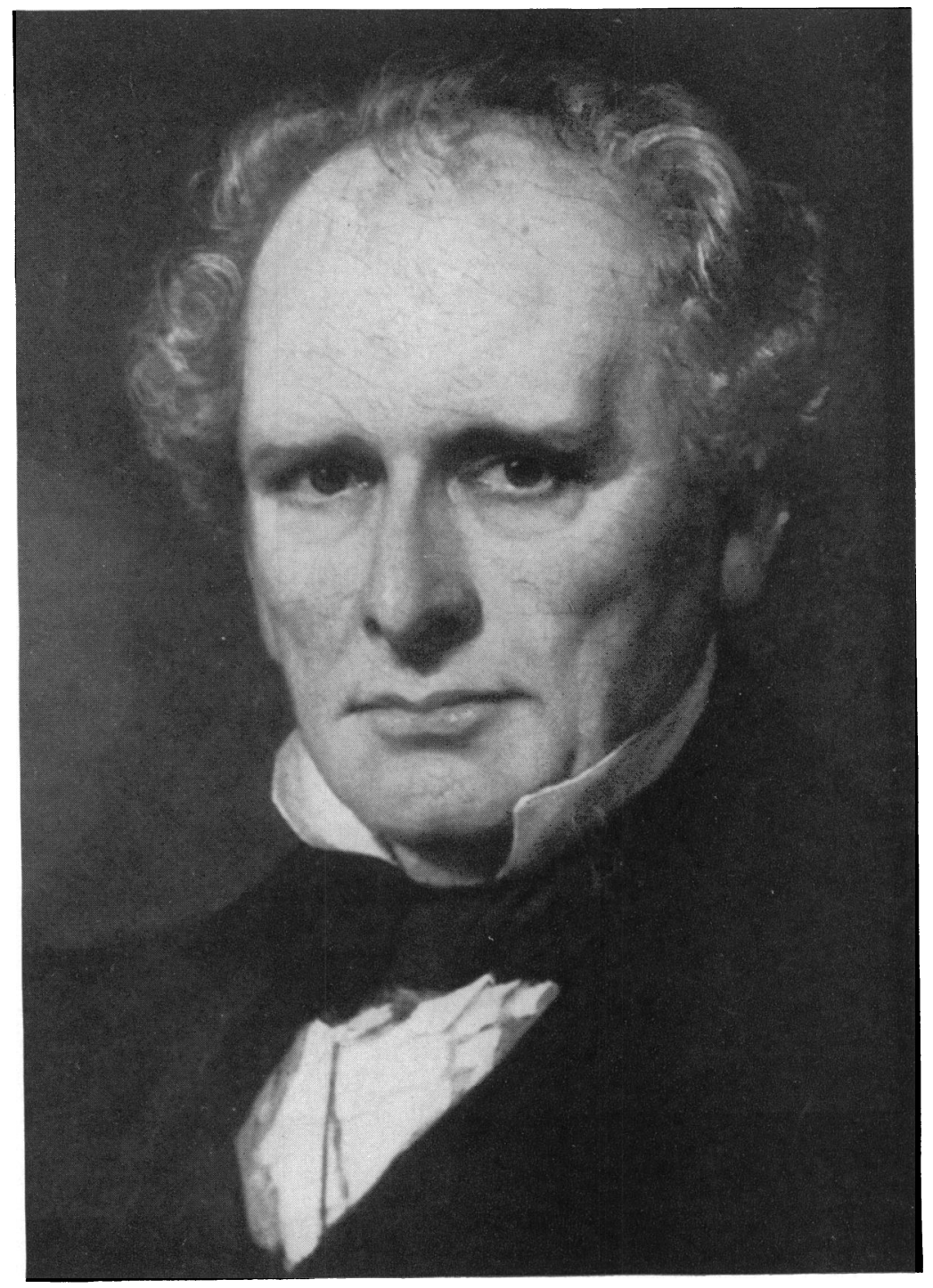

Fig. I

FREDERICK SALMON

From an oil prainting by Francis Grant, R.A. (I895) 


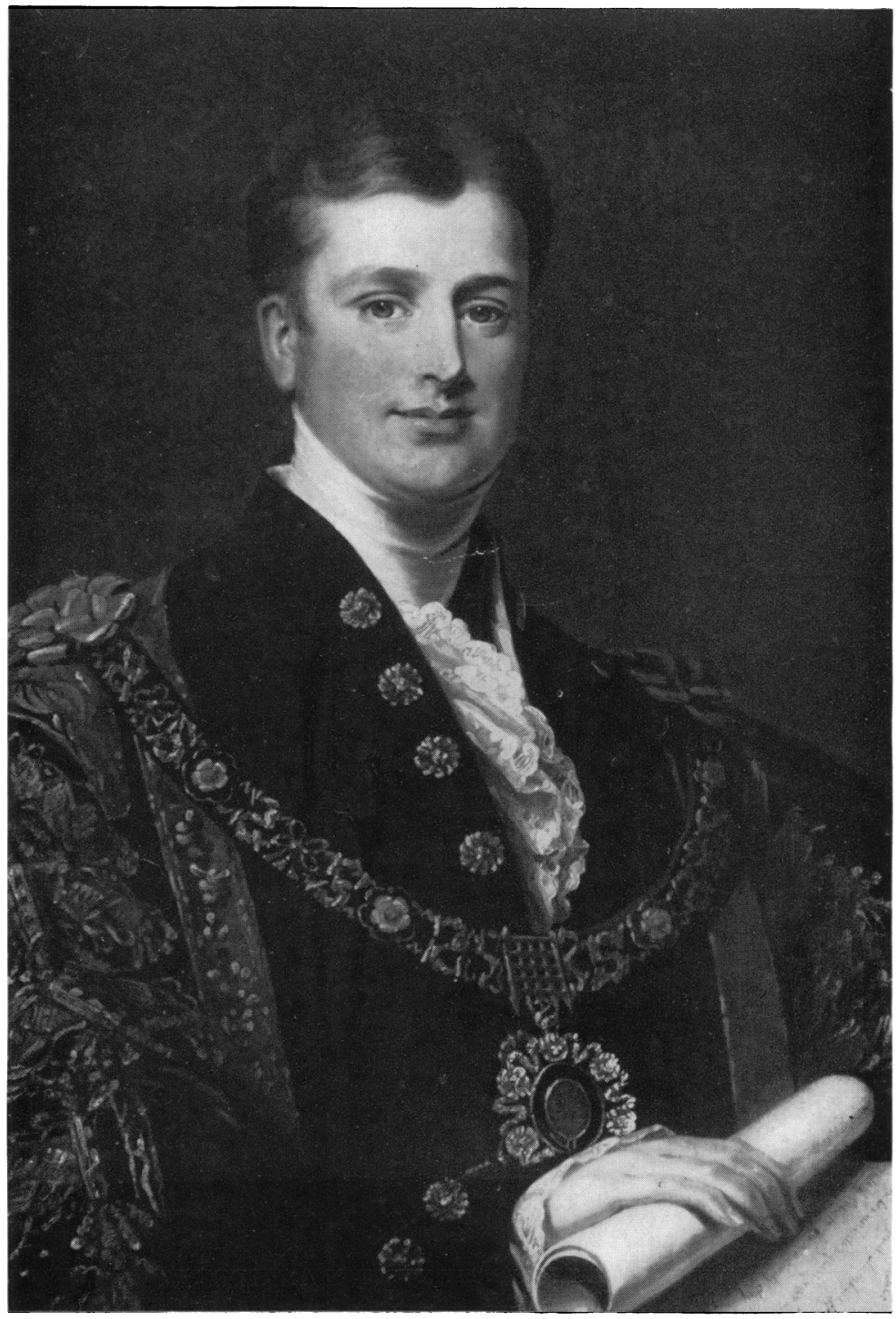

Fig. 2

WILLIAM TAYLOR GOPELAND

From an oil painting by James Ward, R.A. $\left({ }_{1854}\right)$ 


\section{Frederick Salmon: Founder of St. Mark's Hospital, London}

that 'each day's observation convinces him of the extreme prevalence of the disease', which may well occasion surprise today because simple strictures of the rectum are rarely met with at the present time. Yet a third edition of the same book appeared in November 1829 and again a fourth in 1833 . With each successive edition the book grew in size largely by the addition of further case records, some of which gave details of prolonged courses of treatment of rectal strictures by enemas, the use of bougies and minor surgical operations.

Salmon seems to have thought that stricture of the rectum was closely related to stricture of the urethra and (to quote his own words): 'The nearer we assimilate our plan of treatment in the former to that pursued in the latter, the more speedy and satisfactory will be the result'. But it is clear from his case reports that many different pathological conditions which nowadays would be listed separately were grouped by him under the general heading 'Stricture of the rectum'. Some so-called 'strictures' were no doubt stenosing varieties of carcinoma of the lower third of the rectum or anal canal, though probably not many because Salmon was well aware of the nature of cancer; in fact, the eighth chapter of the third edition of his book on rectal stricture is entitled 'On the morbid anatomy, symptoms and treatment of carcinomatous disease of the rectum'. His remarks on the treatment of rectal cancer remind us of how little could be done before the days of radical surgery. 'All we can do is of little avail. ... I fear that the utmost effect we may hope for from our labours, is to soothe the passage of the afflicted sufferer to the grave.' He recommends the frequent application of leeches to the 'orifice of the bowel' (horrible thought!), but strongly deprecates the use of any kind of bougie since 'such treatment will not only be productive of no benefit, but will inevitably aggravate the affliction'.

Salmon's other writings include a small book entitled Practical Observations on Prolapsus of the Rectum (1831) and articles in the Lancet on Stricture of the Rectum in 1832 , and on the Pathology of Disease of the Rectum in 1833 and 1834 .

\section{Controversy with Royal College of Surgeons}

Salmon was an active member of the Medical Society of London and in 1833 was appointed to give the annual oration which is always given at the close of the session. He made use of this occasion to express his strong disapproval of the recent behaviour and general policy of the Royal College of Surgeons, and entitled his oration 'The necessity for an entire change in the constitution and government of the Royal College of Surgeons'. The lecture was given on 8 March 1833 , and was subsequently printed and distributed as a tract (Whittaker, Treacher and Arnot, 1833). A copy of this has been preserved in the library of the Royal College of Surgeons but there is no copy at the Royal Society of Medicine or Medical Society of London. On the title page the author is described as 'Frederick Salmon, F.R.c.s.', but this is incorrect and presumably a printer's error. Salmon was never a Fellow of the Royal College of Surgeons. Actually there were no Fellows of the Royal College of Surgeons until I843 and the oration was delivered ten years before this date. 


\section{Cuthbert E. Dukes}

The oration begins by observing that

There are, we believe, few persons of any reflection who are not satisfied that the government of some of our national institutions requires almost entire reformation; and fewer still who do not consider that nearly all of these are capable of improvement.

Proceeding now from the general to the particular he complained that the Council of the Royal College of Surgeons was a self-elected body and restricted to doctors whose practice was confined to surgery. This does not seem an unreasonable policy today, but Salmon considered it a grave injustice and expressed himself in no uncertain terms. Referring to the College bye-law which regulates the admission of members to the Council he says that this 'evinces an imbecility and narrowness of judgement, indicative of the spirit by which those irresponsible councillors were actuated'.

Salmon's reforming zeal did not exhaust itself on the Royal College of Surgeons alone as is shown by the following continuation:

The most disgraceful abuses exist also in the constitution and government of the College of Physicians, which equally deserve exposure and correction; neither is the Company of Apothecaries altogether exempt from merited condemnation, the same spirit of aggrandizement, the same narrow-minded policy pervades our entire system of medical education.

He concluded his oration by appealing to Fellows of the Medical Society of London to support him in his campaign for reform and ended with this impressive appeal,

Arise then, gentlemen, I implore you, stand forward, do your duty towards accomplishing this necessary and public good, and by such means acquire for yourselves the lasting gratitude of your fellow-countrymen and posterity; together with that never failing and ample reward, the approbation of your own consciences.

Little wonder then that when in 1843 the Council of the Royal College of Surgeons elected some 300 members to the honour of the Fellowship, Frederick Salmon was not included in the number!

\section{Foundation of St. Mark's Hospital}

Salmon's chief claim to be remembered is because he was the Founder of St. Mark's Hospital for Disease of the Rectum and Colon. A fuller account of this is given in the historical chapter which prefaces the Collected Papers of St. Mark's Hospital published in the centenary year 1935 (H. K. Lewis, London). Briefly the story is as follows. In 1835 Salmon acquired premises at i I Aldersgate Street to serve as an 'Infirmary for the Relief of the Poor afflicted with Fistula and other Diseases of the Rectum'; but only seven beds were available so after three years the 'charity' was transferred to more commodious quarters at 38 Charterhouse Square. Here Salmon continued almost single-handed for thirteen years, until in $185 \mathrm{I}$ a site for the hospital was purchased in City Road from the Worshipful Company of Dyers. The existing Dyers' Almshouses were adapted to provide accommodation for twenty-five patients. 


\section{Frederick Salmon: Founder of St. Mark's Hospital, London}

This hospital in City Road was completed and opened officially by the Lord Mayor of London on St. Mark's Day, 25 April 1852, and for this reason given the name 'St. Mark's Hospital for Fistula and other diseases of the Rectum'. The hospital still occupies the same site but it was completely rebuilt between 1894 and 1896 and has been much further enlarged during the last fifty years. At present there are ninety beds and a very large out-patient department. There were no less than twenty thousand out-patient attendances in $195^{8}$.

Salmon met with a good deal of professional opposition when he founded the hospital in 1835 . He had to face this throughout his life and it even pursued him after his decease, for his obituary notice in the British Medical Fournal (1868, I, 4 I) contained what we should rightly call today 'scurrilous innuendos':

Mr. Salmon was well known in London as the founder of St. Mark's Hospital for Fistula and Diseases of Rectum and the author of monographs in the subject of these diseases. How far the course which he took was prompted by difficulties in pursuing a useful and honourable career in a general hospital, where his labours would have been more useful and more instructive, it is now difficult to say. It was, we fully believe, contrary to the best interests both of the profession and of the public.

This uncharitable comment was in keeping with the general policy of the British Medical Fournal at this time. It violently opposed the development of the special hospitals founded in the middle decades of the nineteenth century. The obituary notice continues:

Mr. Salmon acquired a good deal of influence in certain wealthy circles, and we believe enjoyed a lucrative practice. His professional practice was necessarily one of considerable isolation; but he was not without friends amongst men whose friendship is a guarantee of a certain merit of character.

\section{One Hundred Years Ago}

Now in conclusion let us recall the scene one hundred years ago when Salmon retired from the hospital staff in the year 1859 . His departure was felt by the management committee to be a great loss, and they commented on it as follows (23rd Annual Report):

The Founder, Mr. Frederick Salmon, has formally requested permission to resign his appointment as Honorary Surgeon, feeling that the period has arrived when it behoves him to seek the bosom of his family and rest from the labours and anxieties of a life, how spent the records of this Charity bear witness.

As already mentioned the full-length painting which now hangs in the boardroom was presented to Salmon by the Hospital Committee when he retired in 1859 .

Another eloquent tribute of respect was paid by a group of his patients, who decided to make a separate presentation. Having heard that the Hospital Committee were planning to give Salmon an oil-painting, the patients decided to make a presentation of a bust, as an expression of their gratitude to their 


\section{Cuthbert E. Dukes}

surgeon. At the annual meeting of the hospital on 25 January 1859, it was reported

that the poorer patients, judging there would be forthcoming from the wealthier members of society more than sufficient subscriptions for the picture and anxious that some tribute expressive of their deep sense of the mercies received by them (under Providence) at Mr. Salmon's hands should emanate from themselves, and for which they and their friends should subscribe have determined on this bust; which they propose to present to his lady as a token of their gratitude to their benefactor and friend.

'This noble and unprecedented tribute of the humbler patients' was duly presented to Mrs. Salmon in 1860 .

When Salmon retired from practice he went to live at Ombersley near Droitwich. He died on 3 January 1868 , aged 72 . On hearing of his death the comment of his hospital colleagues was

Thus passed from this world a man whose kindness of heart induced, and whose indomitable perseverance enabled him to found an institution for the relief of the sufferings of his poorer fellow creatures which will stand an honourable monument to his memory. 